\title{
Delay of nuclear maturation and reduction in developmental competence of pig oocytes after mineral oil overlay of in vitro maturation media
}

\author{
M. Shimada, N. Kawano and T. Terada \\ Graduate School of Biosphere Sciences, Hiroshima University, \\ Higashi-Hiroshima, Hiroshima 739-8528, Japan
}

\begin{abstract}
Steroid hormones, such as progesterone, oestrogen, androgen and meiosis activating sterols, are secreted from cumulus cells that are stimulated by gonadotrophins during maturation of oocytes in vitro. These steroid hormones may be absorbed by mineral oil or paraffin oil; however, in vitro maturation of pig oocytes is commonly performed using medium covered by oil. In this study, high concentrations of progesterone, oestradiol and testosterone were detected in the culture medium after pig cumulus-oocyte complexes (COCs) were cultured with FSH and $\mathrm{LH}$ for $44 \mathrm{~h}$ in medium without an oil overlay. However, high concentrations of these steroid hormones were not detected in medium when COCs were cultured with the mineral oil overlay. When high concentrations of these steroid hormones were
\end{abstract}

\section{Introduction}

Ovarian folliculogenesis in mammals is mainly under the endocrine control of the pituitary gonadotrophins FSH and $\mathrm{LH}$. Stimulation of both $\mathrm{LH}$ and FSH leads to an increase in oestrogen concentration in the follicular fluid during preovulatory growth and development of ovarian follicles (Ainsworth et al., 1980; Kumar et al., 1992). After the LH surge, the oestrogen concentration of the follicular fluid of preovulatory follicles decreases; this is followed by a decrease in androgen and an increase in progesterone concentration (Ainsworth et al., 1980). Osborn et al. (1986) studied the effects of inhibitors of follicular steroidogenesis on biological changes that occur in oocytes during meiotic maturation. This study showed that addition of a progesterone synthesis inhibitor reduced the proportion of oocytes that reached the MII stage and that addition of an aromatase inhibitor altered protein synthesis in oocytes. During meiotic maturation of cumulus-oocyte complexes (COCs) in vitro, progesterone is also produced by cumulus cells; the concentration of progesterone is increased by stimulation with $\mathrm{LH}, \mathrm{FSH}$ or forskolin in pigs (Xia et al., 1994; Coskun et al., 1995), rats (Zhang and Armstrong, 1989) and cattle (Armstrong et al., 1996). When rat COCs were cultured in vitro with FSH and a cytochrome

Email:mashimad@hiroshima-u.ac.jp secreted by COCs, germinal vesicle breakdown (GVBD) and the activation of p34cdc2 kinase and mitogen-activated protein (MAP) kinase in oocytes occurred earlier in comparison with oocytes cultured in medium covered with mineral oil. Moreover, a decrease in p34 ${ }^{\text {cdc2 }}$ kinase activity during meiotic progression beyond metaphase I was observed in oocytes cultured in conditions under which high concentrations of steroid hormones were secreted by COCs. In addition, the rate of development to the blastocyst stage after IVF was higher in oocytes matured in medium without an oil overlay. These adverse effects of oil may be explained by absorption by the oil of cumulussecreted steroids or by the release of toxic compounds into the medium.

$\mathrm{P} 40_{\mathrm{scc}}$ inhibitor, progesterone secretion was almost completely inhibited and a low rate of oocyte fertilization was observed (Zhang and Armstrong, 1989). Moreover, the addition of oestrogen or testosterone to the maturation medium improved the developmental competence of bovine oocytes after IVF (Younis et al., 1989; Silva and Knight, 2000). These observations imply that the steroid hormones play an important role within the oocyte during meiotic maturation of mammalian oocytes in vivo and in vitro.

Many dynamic morphological and biochemical changes occur to ensure the successful meiotic division during mammalian oocyte maturation. The maturation-phase promoting factor (MPF) is activated after the resumption of meiotic division (Masui and Markert, 1971). MPF is then transiently inactivated, and reactivated again to induce meiosis II (MII) in mouse (Choi et al., 1991), pig (Naito and Toyoda, 1991) and bovine oocytes (Tatemoto and Terada, 1996; Wu et al., 1997). After germinal vesicle breakdown (GVBD), mitogen-activated protein (MAP) kinase is also activated, and activated MAP kinase is required for a further increase in MPF activity and meiotic progression beyond the Ml stage (Inoue et al., 1995; Shimada and Terada, 2001; Shimada et al., 2001a). Naito et al. (1992) reported that high MPF activity in pig oocytes at MIl stage is essential for the development of the male pronucleus. Shimada and Terada (2002a) also showed that both MAP kinase and MPF were 
activated in pig oocytes during meiotic progression to the MII stage, followed by the decrease in CAMP content of oocytes. The decrease in CAMP content of oocytes was induced by binding of progesterone to its receptor in cumulus cells through the reduction of gap junction communication (Shimada and Terada, 2002b). Therefore, it is possible that the secreted steroid hormones, such as progesterone, regulate both cytoplasmic maturation and meiotic cell cycle via activation of both MPF and MAP kinase in pig oocytes.

In vitro maturation (IVM) of pig oocytes is commonly performed using medium covered by paraffin oil or mineral oil (Funahashi et al., 1994; Abeydeera and Day, 1997; Ka et al., 1997; Shimada et al., 2001a). Owing to the high absorbing capacity of paraffin oil or mineral oil, the concentration of oestradiol or progesterone was reduced (Funahashi et al., 1994), indicating that steroid hormones secreted by cumulus cells during IVM might also be absorbed by the paraffin oil or mineral oil. Thus, the IVM system used for pig oocytes, the culture of COCs in the medium covered by paraffin oil or mineral oil, may limit the developmental competence of pig oocytes matured in vitro. However, information about the biological and biochemical differences in oocytes cultured in the medium covered by mineral oil or not covered by mineral oil is very limited. The present study investigated the production of steroid hormones by COCs in maturation medium, the time course of meiotic maturation, p34 cdc2 kinase activity and MAP kinase activity, and the developmental competence of pig oocytes cultured in medium covered or not covered by mineral oil overlay.

\section{Materials and Methods}

\section{Isolation and culture of pig COCs}

Pig COCs were isolated as reported by Shimada and Terada (2001). In brief, ovaries from 5- to 7-month-old prepubertal gilts were collected from a local abattoir. Oocytes were collected with a surgical blade from the surfaces of intact healthy antral follicles that measured $3-8 \mathrm{~mm}$ in diameter. Oocytes that had evenly granulated cytoplasm with at least four layers of unexpanded cumulus oophorus cells were selected and washed three times with the maturation medium mNCSU37 (Petters and Reed, 1991) which contained $20 \mathrm{ng}$ pig FSH ml-1 (NHPP, Torrance, CA), $0.5 \mu \mathrm{g}$ pig $\mathrm{LH} \mathrm{ml}^{-1}$ (NHPP), 10\% (v/v) fetal calf serum (Gibco BRL, Grand Island, NY) and $7 \mathrm{mmol}$ taurine $\mathrm{I}^{-1}$ (Sigma Chemical Co, St Louis, MO).

Twenty COCs were cultured in each well of a four-well multidish (Nunc, Roskilde) containing $500 \mu \mathrm{l}$ of culture medium covered with or without $1 \mathrm{ml}$ of mineral oil (M-8410, Lot no. $21 \mathrm{~K} 0039$, Sigma) at $39^{\circ} \mathrm{C}$ in a humidified atmosphere of $5 \% \quad \mathrm{CO}_{2}$ in air. Control experiments demonstrated that the osmolarity of cultures maintained under each condition varied by $<1 \%$ after $44 \mathrm{~h}$ of culture.
Quantification of progesterone, testosterone and oestradiol in medium by high-performance liquid chromatography (HPLC)-UV analysis

Quantification of steroid hormones by HPLC-UV was based on the procedures reported by Shimada and Terada (2002b). In brief, the medium in which COCs had been cultured for $44 \mathrm{~h}$ was collected into plastic tubes and centrifuged at $10000 \mathrm{~g}$ for $20 \mathrm{~min}$. The resulting supernatant was stored at $-80^{\circ} \mathrm{C}$ until use. Before analysis, $0.5 \mathrm{ml}$ of the medium sample was saponified by the addition

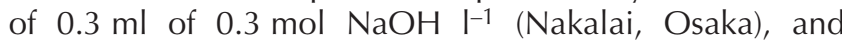
progesterone was extracted from the saponified sample after mixing with $10 \mathrm{ml}$ dichloromethane (Nakalai) for $5 \mathrm{~min}$. After centrifugation, $10 \mathrm{ml}$ dichloromethane fraction was collected into a disposal tube and the solvent from this fraction was removed by vacuum extraction for $120 \mathrm{~min}$ at $5^{\circ} \mathrm{C}$. Samples were reconstituted in $100 \mu \mathrm{l}$ of $50 \%(\mathrm{v} / \mathrm{v})$ methanol solution.

The samples were separated using a reverse-phase CAPCELL PAK column $(2.0 \mathrm{~mm} \times 100 \mathrm{~mm})$ (Shiseido, Tokyo). The solvent delivery system (TSK CCPD, TOSOH) contained $50 \%(\mathrm{v} / \mathrm{v})$ methanol solution and the flow rate was adjusted to $200 \mu \mathrm{l} \mathrm{min}^{-1}$. Samples $(100 \mu \mathrm{l})$ were injected on to columns using an auto sampler (AS-8020, $\mathrm{TOSOH})$. Progesterone, testosterone and oestradiol were detected at 240, 225 or $225 \mathrm{~nm}$, respectively, using a UV detector (UV 8020, TOSOH); peak heights were measured using a computer integrator (Sic chromatocorder 11, $\mathrm{TOSOH}$ ).

The standard curves for progesterone, testosterone and oestradiol were linear, from 0 to $800 \mathrm{ng} \mathrm{m} \mathrm{m}^{-1}$. The intraassay coefficients of variation in medium with $100 \mathrm{ng} \mathrm{ml}-1$ of progesterone, testosterone or oestradiol were 4.15, 5.02 or $4.50 \%$, respectively.

\section{Assessment of nuclear maturation}

At the end of culture, COCs were freed from cumulus cells, mounted on slides, fixed with acetic acid:ethanol (1:3) for $48 \mathrm{~h}$ and stained with aceto-lacmoid before examination under a phase-contrast microscope $(\times 400)$ for evaluation of their chromatin configuration.

\section{Extract preparation for in vitro kinase assay}

Oocytes were lysed according to the technique used by Shimada and Terada (2001). In brief, oocytes were washed several times in PBS and transferred into plastic tubes containing $5 \mu \mathrm{l}$ cell lysis buffer (20.0 mmol Tris $\mathrm{I}^{-1}(\mathrm{pH} 7.5)$, $150.0 \mathrm{mmol} \mathrm{NaCl} \mathrm{I}^{-1}, 1.0 \mathrm{mmol}$ EDTA I-1, $1.0 \mathrm{mmol}$ EGTA $\mathrm{I}^{-1}, 1 \%(\mathrm{v} / \mathrm{v})$ Triton-X100, $2.5 \mathrm{mmol}$ sodium pyrophosphate $\mathrm{I}^{-1}, 1.0 \mathrm{mmol} \beta$-glycerophosphate $\mathrm{I}^{-1}, 1.0 \mathrm{mmol} \mathrm{Na}_{3} \mathrm{VO}_{4}$ $\mathrm{I}^{-1}, 1.0 \mu \mathrm{g}$ leupeptin $\mathrm{ml}^{-1}$ and $1.0 \mathrm{mmol}$ phenylmethylsulphonyl fluoride (PMSF) $\mathrm{I}^{-1}$ ) (Sigma). All chemicals except PMSF were purchased from New England Biolabs (Tozer Road, Beverly, MA). After suspension of the oocytes, the samples were frozen in liquid nitrogen and then sonicated 
using an ultrasonic disruptor (UD-200, TOMY, Tokyo) fitted with CUP HORN (CH-0633, TOMY) three times for $25 \mathrm{~s}$ each at $1^{\circ} \mathrm{C}$. The oocyte extracts were frozen and stored at $-80^{\circ} \mathrm{C}$ just before use.

In vitro $p 34^{c d c 2}$ kinase assay

The p34 cdc2 kinase assay was performed according to the method described by Shimada and Terada (2001). Five microlitres of oocyte extract (containing ten oocytes) was mixed with $45 \mu \mathrm{l}$ kinase assay buffer A composed of 25 mmol Hepes buffer $\mathrm{l}^{-1}$ ( $\mathrm{pH}$ 7.5) (MBL, Nagoya), $10 \mathrm{mmol}$ $\mathrm{MgCl}_{2} \mathrm{I}^{-1}(\mathrm{MBL}), 10 \%(\mathrm{v} / \mathrm{v})$ mouse vimentin peptide solution

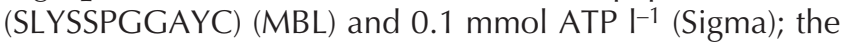
mixture was incubated for $30 \mathrm{~min}$ at $30^{\circ} \mathrm{C}$. The reaction was terminated by the addition of $200 \mu \mathrm{l}$ PBS containing $50 \mathrm{mmol}^{\mathrm{EGTA} \mathrm{I}}{ }^{-1}$ (MBL). The phosphorylation of mouse vimentin peptides was detected using an ELISA (MESACUP cdc2 kinase assay kit (MBL, code no. 5234)). Data were expressed as the fold strength of p34 ${ }^{\text {cdc2 }}$ kinase activity in oocytes just after collection from their follicles. Each independent experiment was repeated four times.

\section{In vitro MAP kinase assay}

A p44/42 MAP kinase assay kit (New England BioLabs) was used for measuring MAP kinase activity. The methods used for the MAP kinase assay were based on those reported by Anas et al. (2000). Five microlitres of oocyte extract (containing 20 oocytes) was mixed with $25 \mu$ l kinase assay buffer B (25 mmol Tris ( $\mathrm{pH} 7.5$ ) $\mathrm{I}^{-1}, 5 \mathrm{mmol} \beta$-glycerophosphate I-1, 2 mmol dithiothreitol I-1, $0.1 \mathrm{mmol} \mathrm{Na}_{3} \mathrm{VO}_{4}$ $\mathrm{I}^{-1}$ and $10 \mathrm{mmol} \mathrm{MgCl}_{2} \mathrm{I}^{-1}$ ), $0.1 \mathrm{mmol}^{\mathrm{ATP}} \mathrm{I}^{-1}$ (Sigma) and $2 \mu \mathrm{g}$ Elk 1 fusion protein, and the mixture was incubated for $30 \mathrm{~min}$ at $30^{\circ} \mathrm{C}$. Chemicals except for ATP were purchased from New England Biolabs. The reaction was terminated by the addition of $10 \mu \mathrm{l}$ of $4 \times$ Laemmli sample buffer; the samples were boiled at $100^{\circ} \mathrm{C}$ for $5 \mathrm{~min}$, and then subjected to $12.5 \%$ SDS-PAGE. The phosphorylation of Elk 1 fusion protein was detected by immunoblot analysis and chemiluminescence detection using anti-phosphospecific Elk 1 antibody. MAP kinase activity is expressed relative to a positive control; 5 ng active MAP kinase is defined as 100. Each independent experiment was repeated four times.

\section{Cryopreservation of boar epididymal semen}

A pair of testes and epididymides from a 2 year old boar (Gottingen miniature pig) was obtained at a local abattoir and transported to the laboratory at $25^{\circ} \mathrm{C}$ within $90 \mathrm{~min}$. Luminal fluid containing spermatozoa was extruded from the distal portion of the cauda epididymidis by air pressure from a syringe. The fluid was diluted with $10 \mathrm{ml}$ modified Hulsenberg VIII diluent (washing medium) according to the method described by Zeng et al. (2001) and rewarmed to $25^{\circ} \mathrm{C}$. Sperm suspension was centrifuged in a $12 \mathrm{ml}$ plastic tube at $800 \mathrm{~g}$ for $10 \mathrm{~min}$ and the supernatant discarded. The precipitated spermatozoa were resuspended in $10 \mathrm{ml}$ washing medium, and then maintained at $25^{\circ} \mathrm{C}$ for $2 \mathrm{~h}$ and centrifuged at $800 \mathrm{~g}$ for $5 \mathrm{~min}$ at $25^{\circ} \mathrm{C}$ to remove the washing medium. The sperm precipitates were diluted in modified BF5 extender (Zeng et al., 2001) to a final concentration of $5 \times 10^{8}$ spermatozoa $\mathrm{ml}^{-1}$ and cooled to $5^{\circ} \mathrm{C}$ within $3 \mathrm{~h}$. Spermatozoa resuspended in BF-5 extender were then mixed with an equal volume of BF-5 extender supplemented with $4 \%(\mathrm{v} / \mathrm{v})$ glycerol as cryoprotectant. After equilibration in glycerol for $15 \mathrm{~min}$, the sperm suspensions were frozen into pellets of $0.2 \mathrm{ml}$ on solid $\mathrm{CO}_{2}$. After $30 \mathrm{~min}$, the pellets were transferred into liquid nitrogen for storage.

\section{IVF}

After $44 \mathrm{~h}$ of IVM of oocytes in the medium covered with or without mineral oil, cumulus cells were removed with $0.01 \%(\mathrm{w} / \mathrm{v})$ hyaluronidase (Sigma) in the maturation medium and washed three times with the fertilization medium: modified Tris-buffered medium (mTBM) supplemented with $0.1 \%(\mathrm{w} / \mathrm{v})$ BSA (Fraction V; Sigma A 7888)

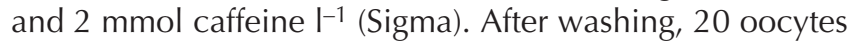
were placed in $50 \mu \mathrm{l}$ drops of the fertilization medium that had been covered with mineral oil in a $35 \times 10 \mathrm{~mm}^{2}$ polystyrene culture dish (Becton Dickinson and Co, Lincoln Park, NJ). The dishes were kept in the incubator for about 30 min until spermatozoa were added for fertilization. Frozen epididymal spermatozoa were thawed and washed by centrifugation at $700 \mathrm{~g}$ for $5 \mathrm{~min}$ in washing medium: mTBM supplemented with $0.1 \%(\mathrm{w} / \mathrm{v})$ BSA (Fraction $\mathrm{V}$; Sigma A 7888). The sperm pellet was resuspended and pre-cultured for $60 \mathrm{~min}$ in pre-culture medium: mTBM supplemented with $10 \%(\mathrm{v} / \mathrm{v})$ fetal calf serum and $2 \mathrm{mmol}$ caffeine $\mathrm{I}^{-1}$. The concentration of spermatozoa during preculture was $2 \times 10^{8}$ cells $\mathrm{ml}^{-1}$. The pre-cultured spermatozoa were diluted to $2 \times 10^{6}$ cells $\mathrm{ml}^{-1}$ in the fertilization medium and $50 \mu \mathrm{l}$ of this sperm suspension was added to $50 \mu \mathrm{l}$ of the fertilization medium that contained 20 oocytes (final concentration of spermatozoa, $1 \times 10^{6}$ cell $\mathrm{ml}^{-1}$ ). Oocytes were co-cultured with spermatozoa for $6 \mathrm{~h}$ at $39^{\circ} \mathrm{C}$ in an atmosphere of $5 \% \mathrm{CO}_{2}$ in air. The mTBM used for IVF was essentially the same as that used by Abeydeera and Day (1997). As the pH of basic mTBM just after preparation is about 9.8-10.0, final IVF medium was kept in the incubator (an atmosphere of $5 \% \mathrm{CO}_{2}$ in air at $39^{\circ} \mathrm{C}$ ) for $18-24 \mathrm{~h}$ to stabilize the $\mathrm{pH}$ to $7.2-7.3$ before use.

\section{In vitro production of embryos}

After sperm-oocyte co-incubation, putative zygotes were washed three times in in vitro production medium and transferred to $100 \mu \mathrm{l}$ drop of the same medium. The in vitro production medium was NCSU 37 containing 0.4\% BSA (Fraction V, Sigma, A 8022). At 12, 48 and $144 \mathrm{~h}$ after IVF, the proportions of pronuclear formation, cleavage rate and blastocyst formation, respectively, were evaluated. 
Table 1. Concentration of steroid hormones in the medium in which pig cumulus-oocyte complexes (COCs) were cultured for $44 \mathrm{~h}$ covered or not covered by mineral oil

\begin{tabular}{lccc}
\hline Medium & $\begin{array}{c}\text { Progesterone } \\
\left(\mathrm{ng} \mathrm{ml}^{-1}\right)\end{array}$ & $\begin{array}{c}\text { Testosterone } \\
\left(\mathrm{ng} \mathrm{ml}^{-1}\right)\end{array}$ & $\begin{array}{c}\text { Oestradiol } \\
\left(\mathrm{ng} \mathrm{ml}^{-1}\right)\end{array}$ \\
\hline Covered by $1 \mathrm{ml}$ mineral oil & $2.5 \pm 0.4$ & $3.3 \pm 0.8$ & $0.7 \pm 0.1$ \\
Not covered by mineral oil & $64.2 \pm 5.4^{*}$ & $5.3 \pm 1.4$ & $1.2 \pm 0.2$ \\
\hline
\end{tabular}

Values are mean \pm SEM of four replicates

*Significantly different from value for medium covered by mineral oil $(P<0.05)$.

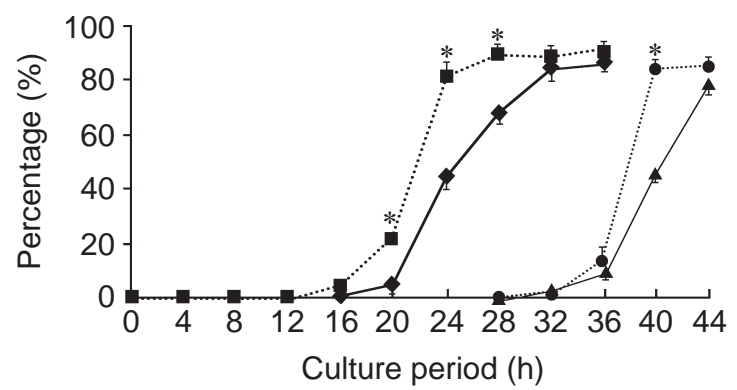

Fig. 1. Time-dependent changes in nuclear status of pig oocytes cultured in medium either covered by $1 \mathrm{ml}$ mineral oil or without mineral oil covering. Cumulus-oocyte complexes (COCs) cultured in medium $(\checkmark)$ with oil or $(\mathbf{\square})$ without oil that reached the germinal vesicle breakdown $(\mathrm{GVBD})$ stage; COCs cultured in medium $(\mathbf{\Delta})$ with oil or $(-$ without oil that reached the MIl stage. *Significant difference compared with oocytes matured in the medium covered with oil $(P<0.05)$. Values are mean \pm SEM of four replicates.

\section{Statistical analysis}

Statistical analyses of all data from three or four replicates were carried out by one-way ANOVA followed by Duncan's multiple ranges test using STATVIEW (Abacus Concepts, Inc, Berkeley, CA). All percentage data were subjected to arcsine transformation before statistical analysis.

\section{Results}

The concentrations of progesterone, testosterone and oestradiol in media produced by cumulus cells surrounding oocytes during meiotic maturation

The concentration of progesterone in the medium in which COCs were cultured under mineral oil was significantly lower compared with the concentration in the medium in which COCs were cultured for $44 \mathrm{~h}$ without the oil overlay (Table 1). Both testosterone and oestradiol concentrations were slightly higher in the medium without the mineral oil overlay in comparison with that of medium covered by the oil, although these differences were not significant.

Time course of GVBD and meiotic progression reaching the MII stage of oocytes cultured in medium covered with or without mineral oil

A small proportion of the oocytes cultured in the medium without the mineral oil overlay underwent GVBD at $16 \mathrm{~h}$ of culture, but this did not occur in the oocytes cultured in medium covered with mineral oil (Fig. 1). In oocytes cultured in medium covered with mineral oil, GVBD occurred at $20 \mathrm{~h}$ of culture. The proportion of oocytes that underwent GVBD after culture for 20, 24 and $28 \mathrm{~h}$ in medium covered with mineral oil was significantly lower than that of oocytes cultured in medium without the oil overlay $(P<0.05)$. However, at $32 \mathrm{~h}$ of culture, COCs produced a similar proportion of oocytes at the GVBD stage in each cultivation system.

At $40 \mathrm{~h}$ of culture, the proportion of oocytes that reached the MIl stage in medium without the oil overlay was significantly higher $(P<0.05)$ than that of oocytes cultured in medium covered with oil; a further $4 \mathrm{~h}$ of culture ( $44 \mathrm{~h}$ ) was required for a similar proportion of oocytes to reach the MII stage when cultured in medium covered with oil.

Time-dependent changes of $p 34^{c d c 2}$ kinase activity and MAP kinase activity in oocytes cultured in medium covered with or without mineral oil

At $20 \mathrm{~h}$ of culture, p34cdc2 kinase activity was low in oocytes cultured in medium covered with mineral oil (Fig. 2 ); whereas a significant increase in kinase activity was observed, reaching a peak at $28 \mathrm{~h}$ of culture, in the oocytes cultured for $20 \mathrm{~h}$ without the oil overlay (Fig. 2). In oocytes cultured in medium without the oil overlay, the activity of p34 ${ }^{\text {cdc2 }}$ kinase significantly decreased $(P<0.05)$ at $36 \mathrm{~h}$ and then increased until it reached a second peak at $40-44 \mathrm{~h}$ of maturation (Fig. 2). In the oocytes cultured in medium covered with the mineral oil, p34 cdc2 kinase activity was also increased at $24 \mathrm{~h}$, reaching maximum activity at $28 \mathrm{~h}$, and remained high for up to $44 \mathrm{~h}$ (Fig. 2). A significant difference in the activity of p34cdc2 kinase was observed between the oocytes cultured in medium covered with and without mineral oil only at 20,24 28 and 36 h of maturation (Fig. 2).

At $24 \mathrm{~h}$ of culture of COCs in medium covered with mineral oil, a low MAP kinase activity was detected in the oocytes (Fig. 3). However, a significant increase in this activity was observed in oocytes cultured at $24 \mathrm{~h}$ without the oil overlay (Fig. 3). MAP kinase activity of oocytes cultured in medium without the oil overlay was significantly higher compared with that in COCs cultured in medium covered with oil at $28 \mathrm{~h}$ or $32 \mathrm{~h}$ of culture (Fig. 3). MAP kinase activity of oocytes cultured in the medium covered 


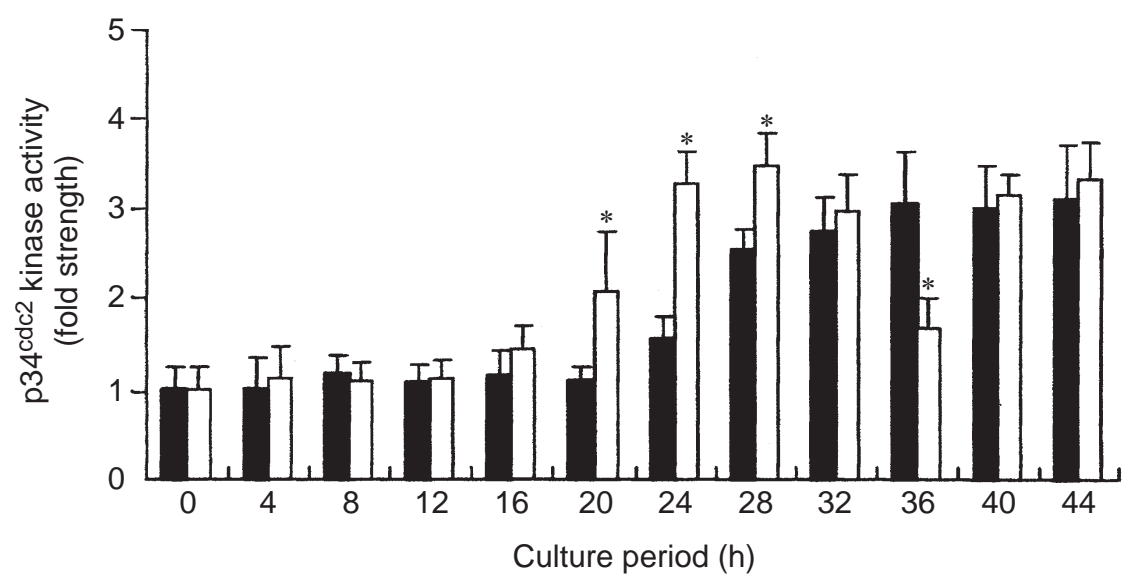

Fig. 2. Time-dependent changes of $\mathrm{p} 34^{\mathrm{cdc} 2}$ kinase in pig oocytes cultured in medium covered by $1 \mathrm{ml}$ mineral oil ( $\square$ ) or without the oil covering $(\square)$. Cumulus-oocyte complexes (COCs) were cultured in medium either covered with mineral oil or without mineral oil overlay. Data are expressed as fold strength of p34 ${ }^{\text {cdc2 }}$ kinase activity in oocytes immediately after collection from the follicles. *Significant difference compared with oocytes matured in the medium covered with oil $(P<0.05)$. Values are mean \pm SEM of four replicates.

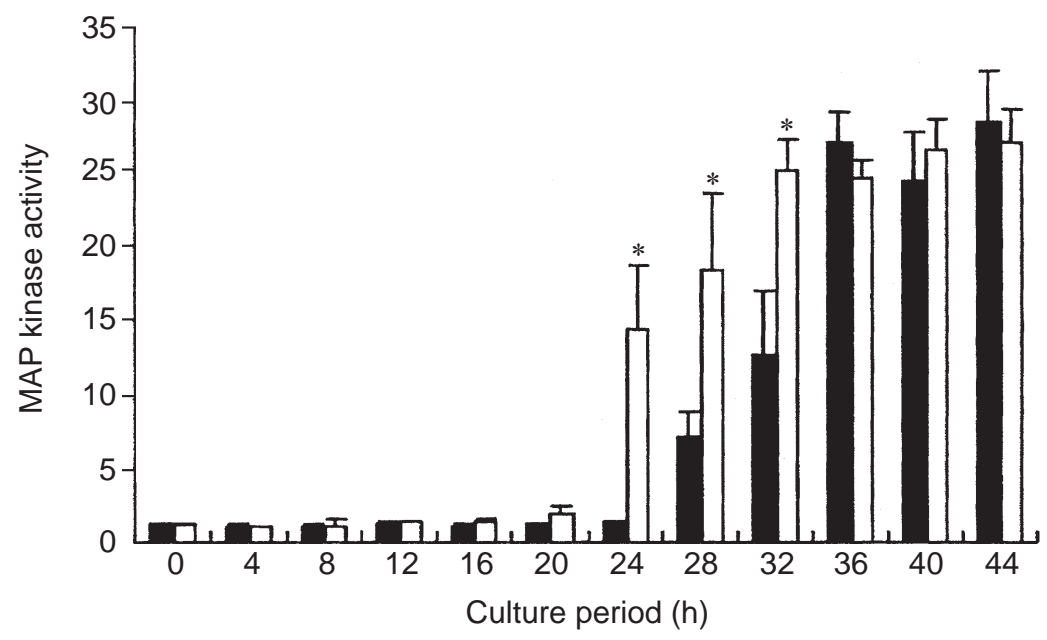

Fig. 3. Time-dependent changes of microtubule-associated protein (MAP) kinase activity in pig oocytes cultured in the medium covered by $1 \mathrm{ml}$ mineral oil (ם) or without the oil covering ( $\square$ ). Cumulus-oocyte complexes (COCs) were cultured in medium either covered by mineral oil or in the medium without mineral oil overlay. Activity is expressed as fold MAP kinase activity in which positive control ( 5 ng active MAP kinase activity) is defined as 100 . * Significant difference compared with oocytes matured in the medium covered with oil $(P<0.05)$. Values are mean \pm SEM of four replicates.

with mineral oil then gradually increased, and at $36 \mathrm{~h}$ of culture, MAP kinase activities of oocytes cultured in medium covered with and without mineral oil were not significantly different (Fig. 3).

\section{Effects the mineral oil overlay during meiotic maturation on the pronuclear formation, cleavage rate and blastocyst formation after IVF}

At $12 \mathrm{~h}$ after insemination, there was no difference in the incidence of maturation, penetration and monospermy between oocytes matured in medium covered with mineral oil and those matured without the oil covering (Table 2). However, the proportion of male pronuclear formation in oocytes matured without the oil overlay was significantly higher than that in oocytes cultured in medium covered with oil. The number of spermatozoa in penetrated oocytes was slightly higher in oocytes matured in medium covered with mineral oil in comparison with that of oocytes matured without the oil covering; however, this increase was not significant. Moreover, the absence of mineral oil during meiotic maturation improved the proportion of cleaved 
Table 2. Sperm penetration of pig oocytes matured in medium covered by $1 \mathrm{ml}$ mineral oil (+) or not covered with mineral oil (-) for $44 \mathrm{~h}$ and then fertilized in vitro

\begin{tabular}{|c|c|c|c|c|c|c|}
\hline \multirow[b]{2}{*}{ Mineral oil } & \multirow{2}{*}{$\begin{array}{c}\text { Number of } \\
\text { oocytes } \\
\text { examined }\end{array}$} & \multicolumn{4}{|c|}{ Percentage of oocytes } & \multirow{2}{*}{$\begin{array}{c}\text { Number of } \\
\text { spermatozoa } \\
\text { per oocyte }^{\ddagger}\end{array}$} \\
\hline & & Matured & Penetrated* & Monospermy ${ }^{\dagger}$ & MPN formed ${ }^{\dagger}$ & \\
\hline+ & 60 & $83.3 \pm 10.4$ & $82.1 \pm 4.7$ & $58.1 \pm 7.3$ & $68.3 \pm 2.7^{a}$ & $1.78 \pm 0.14$ \\
\hline- & 60 & $86.7 \pm 2.9$ & $86.7 \pm 8.3$ & $68.7 \pm 5.6$ & $88.8 \pm 4.0^{\mathrm{b}}$ & $1.51 \pm 0.18$ \\
\hline
\end{tabular}

Values are mean \pm SEM of three replicates

abValues with no common superscript within columns are significantly different $(P<0.05)$.

*Percentage of oocytes matured.

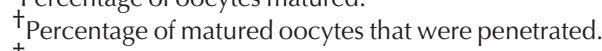

${ }^{\ddagger}$ Number of spermatozoa in penetrated oocytes.

MPN: male pronucleus.

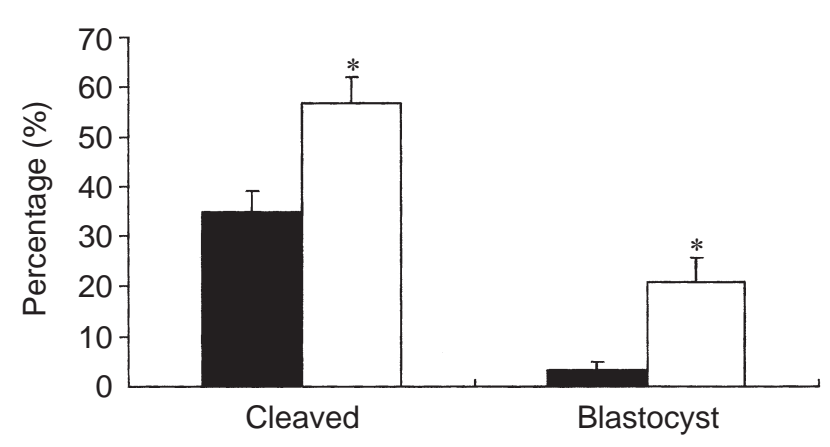

Fig. 4. Early development in vitro of pig oocytes that were matured in the medium covered with ( $\square$ ) or without the mineral oil overlay $(\square)$ and then fertilized in vitro. Cumulus-oocyte complexes (COCs) were matured in medium covered by $1 \mathrm{ml}$ mineral oil or in medium without mineral oil overlay. ${ }^{*}$ Significant difference compared with oocytes matured in the medium covered with oil $(P<0.05)$. Values are mean \pm SEM of four replicates. $n=80$ oocytes per group.

oocytes at 2 days after insemination $(56.6 \pm 5.4 \%)$ and the proportion of oocytes reaching the blastocyst stage at 6 day of culture $(20.8 \pm 4.8 \%)$ in comparison with oocytes matured in the medium covered with oil $(35.0 \pm 4.2 \%$ and $3.3 \pm 1.6 \%$, respectively) (Fig. 4 ).

\section{Discussion}

During in vitro meiotic maturation of oocytes, progesterone and oestradiol are secreted by COCs of pigs (Xia et al., 1994), rats (Zhang and Armstrong, 1989) and cattle (Armstrong et al., 1996). In the present study, the increase in progesterone concentrations in the culture medium was produced by FSH- and LH-stimulated pig COCs; however, the high concentration of progesterone was not detected in the medium in which COCs were cultured with $\mathrm{LH}$ and $\mathrm{FSH}$ for $44 \mathrm{~h}$ under mineral oil. Both testosterone and oestradiol concentrations in the medium in which COCs were cultured without the oil covering were slightly higher than those in the medium covered with oil. Funahashi et al. (1994) reported that during in vitro culture of pig COCs exogenous oestradiol and progesterone were absorbed by the paraffin oil which covered the medium. It is possible that the solubility of progesterone in mineral oil is higher than that of testosterone and oestradiol. However, Erbach et al. (1995) showed that zinc is a possible toxic contaminant of silicone oil in microdrop cultures of mouse embryos. A silicone oil overlay also affects bovine embryonic development (Van Soom et al., 2001). Thus, the low secretion of steroid hormones by cumulus cells into the medium may be explained by the absorption of the hormones by the mineral oil or by the adverse effects of toxic compounds in mineral oil on the production of steroid hormones.

The high concentrations of steroid hormones secreted by COCs accelerated GVBD and activation of p34cdc2 kinase in oocytes cultured without the oil overlay in comparison with oocytes cultured under mineral oil. Osborn et al. (1986) reported that the addition of aminoglutethimide into gonadotrophin-containing medium produced low concentrations of progesterone and an increase in the proportion of oocytes arrested at the germinal vesicle stage in ovine oocytes. Shimada and Terada (2002b) showed that when pig COCs were cultured with $\mathrm{LH}, \mathrm{FSH}$ and $0.5 \times 10^{-3} \mathrm{~mol}$ aminoglutethimide $\mathrm{I}^{-1}$, progesterone production and GVBD were almost completely inhibited, and the inhibition on GVBD was overcome by addition of progesterone. Moreover, the binding of progesterone that was secreted by $\mathrm{LH}$ - and FSH-stimulated cumulus cells to its receptor reduces connexin-43 content in cumulus cells (Shimada et al., 2001b; Shimada and Terada, 2002b). The reduction of connexin-43 induces the reduction of gap junction communication which is necessary for GVBD in pig oocytes (Isobe et al., 1998; Isobe and Terada, 2001). At this time, the concentration of progesterone secreted by $\mathrm{FSH}$ and LH-stimulated cumulus cells is high (Shimada and Terada, $2002 b)$. Thus, the high concentration of progesterone in the culture medium produced the reduction of gap junction communication in the outer layers of cumulus cells, resulting in acceleration of meiotic resumption in pig oocytes.

At the MI stage, high MAP kinase activity induces a further increase in p34cdc2 kinase activity in pig oocytes (Shimada et al., 2001a). After GVBD in pig oocytes, a 
further increase of MPF activity is required for meiotic progression beyond the MI stage (Naito et al., 1992). Increasing MPF activity stimulates the ubiquitin proteolysis pathway which induces degradation of cyclin B, and triggers a decrease in MPF activity, leading to meiotic progression beyond the Ml stage (Glotzer et al., 1991; Hampl and Eppig, 1995). The present study showed that after GVBD, MAP kinase activation was accelerated, and p34 ${ }^{\text {cdc2 }}$ kinase activity was higher in oocytes cultured in the presence of a high concentration of steroid hormones in comparison with oocytes cultured under the oil overlay. Moreover, a decline in p34cdc2 kinase activity was detected in oocytes cultured for $36 \mathrm{~h}$ with a high concentration of steroid hormones. Asynchronous meiotic progression to the MIl stage was observed in oocytes cultured in medium covered with mineral oil, which was also observed in other studies with pig oocytes (Motlik and Fulka, 1976; Funahashi and Day, 1993). Therefore, the decrease in mean activity of p34 ${ }^{\text {cdc2 }}$ kinase in the oocytes cultured under the mineral oil cannot be detected by in vitro kinase assay using 10 oocytes. These results support the hypothesis that high concentrations of the steroid hormones produce an earlier activation of MAP kinase after GVBD, which accelerates further increase of p34 ${ }^{\text {cdc2 }}$ kinase activity at the MI stage and induces more synchronous meiotic progression to the MII stage.

The secretion of progesterone by $\mathrm{FSH}-$ and $\mathrm{LH}-$ stimulated cumulus cells plays an important role in the acquisition of developmental competence in rat oocytes (Zhang and Armstrong, 1989). Moreover, meiosis-activating sterols which were purified from human follicular fluid $(4,4-$ dimethyl- $5 \alpha$-cholest-8,14,24-trien-3 $\beta$-ol) stimulate meiotic and cytoplasmic maturation of human and mouse oocytes (Byskov et al., 1995; Cavilla et al., 2001). This sterol was synthesized by COCs in response to FSH stimulation, and was also absorbed by the oil phase that covered the maturation medium (Byskov et al., 1997). In the present study, absence of mineral oil that covers the maturation medium improves the rate of early embryonic development to the blastocyst stage after IVF, concomitantly with an increase of the concentration of progesterone, oestradiol and testosterone. These results indicate that substances absorbed by mineral oils, such as progesterone, oestradiol, testosterone and meiosis-activating sterols, which are secreted by cumulus cells and oocytes, play an important role in developmental competence of in vitro matured pig oocytes. However, further study is required to clarify the role of substances absorbed by mineral oil in cytoplasmic maturation of pig oocytes. It is thought that culture of pig COCs in vitro in the medium covered by mineral oil limits the developmental competence of oocytes.

In conclusion, the concentrations of progesterone, oestradiol and testosterone in medium was increased by FSH- and LH-stimulated pig COCs. However, high concentrations of these steroid hormones were not detected in the medium in which COCs were cultured with $\mathrm{LH}$ and FSH for $44 \mathrm{~h}$ in the presence of mineral oil. The high concentration of the steroid hormones secreted by COCs accelerated GVBD and activated p34cdc2 kinase and MAP kinase in oocytes in comparison with those of oocytes cultured under the mineral oil. Moreover, a decrease in p34cdc2 kinase activity was observed during meiotic progression beyond the Ml stage in oocytes cultured under the condition of high concentration of steroid hormones secreted by COCs. In addition, in the absence of mineral oil over the maturation medium the rate of early embryonic development to the blastocyst stage after IVF was improved. These results indicate that mineral oil overlay during in vitro meiotic maturation reduces fully maturation of pig oocytes.

The authors are grateful to M. Fujita, Laboratory of Applied Animal Physiology, Hiroshima University, for technical advice on the use of HPLC-UV analysis. The authors thank N. Isobe and A. Barua for insightful comments and suggestions concerning the manuscript. The authors extend their thanks to staff of the Meat Inspection Office in Hiroshima City for supplying the porcine ovaries. Pig FSH and LH were kindly provided by A. F. Parlow, National Hormone and Pituitary Program, National Institute of Diabetes and Digestive and Kidney Disease. This work was partly supported by Grant-in-Aid for Scientific Research (M. Shimada, No. 14760179; T. Terada, No. 12660256) from Japan Society for the Promotion of Science.

\section{References}

Abeydeera LR and Day BN (1997) Fertilization and subsequent development in vitro of pig oocytes inseminated in a modified Trisbuffered medium with frozen-thawed ejaculated spermatozoa Biology of Reproduction 57 729-734

Ainsworth L, Tsang BK, Downey BR, Marcus GJ and Armstrong DT (1980) Inter-relationships between follicular fluid steroid levels, gonadotropic stimuli and oocyte maturation during preovulatory development of porcine follicles Biology of Reproduction 23 621-627

Anas MA, Shojo A, Shimada M and Terada T (2000) Effects of wortmannin on the kinetics of GVBD and the activities of the maturation-promoting factor and mitogen-activated protein kinase during bovine oocyte maturation in vitro. Theriogenology 53 1797-1806

Armstrong DT, Xia P, de Gannes G, Tekpetey FR and Khamsi F (1996) Differential effects of insulin-like growth factor-I and follicle-stimulating hormone on proliferation and differentiation of bovine cumulus cells and granulosa cells Biology of Reproduction 54 331-338

Byskov AG, Andersen CY, Nordholm L, Thogersen H, Xia G, Wassmann O, Andersen JV, Guddal E and Roed T (1995) Chemical structure of sterols that activate oocyte meiosis Nature 374 559-562

Byskov AG, Yding Andersen C, Hossaini A and Guoliang X (1997) Cumulus cells of oocyte-cumulus complexes secrete a meiosis-activating substance when stimulated with FSH Molecular Reproduction and Development 46 296-305

Cavilla JL, Kennedy CR, Baltsen M, Klentzeris LD, Byskov AG and Hartshorne GM (2001) The effects of meiosis activating sterol on in vitro maturation and fertilization of human oocytes from stimulated and unstimulated ovaries Human Reproduction 16 547-555

Choi T, Aoki F, Mori M, Yamashita M, Nagahama Y and Kohmoto K (1991) Activation of $\mathrm{p} 34^{\mathrm{cdc} 2}$ protein kinase activity in meiotic and mitotic cell cycle in mouse oocytes and embryos Development 113 789-795

Coskun S, Uzumcu M, Lin YC, Friedman CI and Alak BM (1995) Regulation of cumulus cell steroidogenesis by the porcine oocyte and preliminary characterization of oocyte-produced factor(s) Biology of Reproduction $53670-675$

Erbach GT, Bhatnagar P, Baltz JM and Biggers JD (1995) Zinc is a possible toxic contaminant of silicone oil in microdrop cultures of preimplantation mouse embryos Human Reproduction 10 3248-3254 
Funahashi H and Day BN (1993) Effects of follicular fluid at fertilization in vitro on sperm penetration in pig oocytes Journal of Reproduction and Fertility 99 97-103

Funahashi H, Cantley T and Day BN (1994) Different hormonal requirements of pig oocyte-cumulus complexes during maturation in vitro. Journal of Reproduction and Fertility 101 159-165

Glotzer M, Murray AW and Kirschner MW (1991) Cyclin is degraded by the ubiquitin pathway Nature 349 132-138

Hampl A and Eppig JJ (1995) Analysis of mechanism(s) of metaphase I arrest in maturing mouse oocytes Development 121 925-933

Inoue M, Naito K, Aoki F, Toyoda Y and Sato E (1995) Activation of mitogen-activated protein kinase during meiotic maturation in porcine oocytes Zygote 3 265-271

Isobe $\mathbf{N}$ and Terada T (2001) Effect of the factor inhibiting germinal vesicle breakdown on the disruption of gap junctions and cumulus expansion of pig cumulus-oocyte complexes cultured in vitro. Reproduction 121 249-257

Isobe N, Maeda T and Terada T (1998) Involvement of meiotic resumption in the disruption of gap junctions between cumulus cells attached to pig oocytes Journal of Reproduction and Fertility 113 167-172

Ka HH, Sawai K, Wang WH, Im KS and Niwa K (1997) Amino acids in maturation medium and presence of cumulus cells at fertilization promote male pronuclear formation in porcine oocytes matured and penetrated in vitro. Biology of Reproduction 57 478-483

Kumar J, Osborn JC, Cameron AW and Trounson AO (1992) Follicular steroidogenesis and oocyte maturation after superovulation of goats (Capra hircus) with gonadotrophins Journal of Reproduction and Fertility $95371-383$

Masui Y and Markert GE (1971) Cytoplasmic control of nuclear behavior during meiotic maturation of frog oocytes Journal of Experimental Zoology 177 129-146

Motlik J and Fulka J (1976) Breakdown of the germinal vesicle in pig oocytes in vivo and in vitro. Journal of Experimental Zoology 198 155-162

Naito K and Toyoda Y (1991) Fluctuation of histone H1 kinase activity during meiotic maturation in porcine oocytes Journal of Reproduction and Fertility 93 467-473

Naito K, Daen FP and Toyoda Y (1992) Comparison of histone H1 kinase activity during meiotic maturation between two types of porcine oocytes matured in different media in vitro. Biology of Reproduction 47 43-47

Osborn JC, Moor RM and Crosby IM (1986) Effect of alterations in follicular steroidogenesis on the nuclear and cytoplasmic maturation of ovine oocytes Journal of Embryology and Experimental Morphology 98 187-208

Petters RM and Reed ML (1991) Addition of taurine or hypotaurine to culture medium improves development of one- and two-cell pig embryos in vitro. Theriogenology 35253

Shimada M and Terada T (2001) PI 3-kinase in cumulus cells and oocytes is responsible for activation of oocyte MAP kinase during meiotic progression beyond the MI stage in pigs Biology of Reproduction 64 1106-1114
Shimada M and Terada T (2002a) Roles of cAMP in regulation of both MAP kinase and p34 cdc2 kinase activity during meiotic progression, especially beyond the MI stage Molecular Reproduction and Development 62 124-131

Shimada M and Terada T (2002b) FSH and LH induce progesterone production and progesterone receptor synthesis in cumulus cells, a requirement for meiotic resumption in porcine oocytes Molecular Human Reproduction 8 612-618

Shimada M, Zeng WX and Terada T (2001a) Inhibition of PI 3-kinase or MEK leads to suppression of $\mathrm{p} 34^{\mathrm{cdc} 2}$ kinase activity and meiotic progression beyond the $\mathrm{MI}$ stage in porcine oocytes surrounded with cumulus cells Biology of Reproduction 65 442-448

Shimada M, Maeda T and Terada T (2001b) Dynamic changes of connexin43, gap junctional protein, in outer layers of cumulus cells are regulated by PKC and PI 3-Kinase during meiotic resumption in porcine oocytes Biology of Reproduction 64 1255-1263

Silva CC and Knight PG (2000) Effects of androgens, progesterone and their antagonists on the developmental competence of in vitro matured bovine oocytes Journal of Reproduction and Fertility 119 261-269

Tatemoto H and Terada T (1996) Activation of p34cdc2 kinase around the meiotic resumption in bovine oocytes cultured in vitro. Theriogenology 45 427-437

Van Soom A, Mahmoudzadeh AR, Christophe A, Ysebaert MT and de Kruif A (2001) Silicone oil used in microdrop culture can affect bovine embryonic development and freezability Reproduction in Domestic Animals 36 169-176

Wu B, Ignotz G, Currie WB and Yang X (1997) Dynamics of maturationpromoting factor and its constituent proteins during in vitro maturation of bovine oocytes Biology of Reproduction 56 253-259

Xia P, Tekpetey FR and Armstrong DT (1994) Effect of IGF-I on pig oocyte maturation, fertilization and early embryonic development in vitro, and on granulosa and cumulus cell biosynthetic activity Molecular Reproduction and Development 38 373-379

Younis AI, Brackett BG and Fayrer-Hosken RA (1989) Influence of serum and hormones on bovine oocyte maturation and fertilization in vitro. Gamete Research 23 189-201

Zeng WX, Shimada M, Isobe N and Terada T (2001) Survival of boar spermatozoa frozen in diluent of varying osmolality Theriogenology $\mathbf{5 6}$ $447-458$

Zhang X and Armstrong DT (1989) Effects of follicle-stimulating hormone and ovarian steroids during in vitro meiotic maturation on fertilization of rat oocytes Gamete Research 23 267-277

Received 10 May 2002.

First decision 20 June 2002

Revised manuscript received 27 June 2002.

Accepted 5 July 2002. 